\title{
MODELING AND OPTIMIZATION OF IN SYRINGE MAGNET STIRRING ASSISTED-DISPERSIVE LIQUID- LIQUID MICROEXTRACTION METHOD FOR EXTRACTION OF CADMIUM FROM FOOD SAMPLES BY ARTIFICIAL NEURAL NETWORK AND GENETIC ALGORITHM
}

\author{
ALI MOHAMMADZADEH, MAJID RAMEZANI* \\ Department of Chemistry, Arak Branch, Islamic Azad University, Arak, Iran
}

\begin{abstract}
For the first time, artificial neural network (ANN) and genetic algorithm (GA) have been employed to modeling and optimization of in syringe magnet stirring assisted dispersive liquid-liquid microextraction (IS-MSA-DLLME) method for extraction of cadmium from food samples and determined by flame atomic absorption spectrometry. Based on one factor at a time optimization method, the different input variables for modeling were chosen as $\mathrm{pH}$ of the solution, extraction volume, stirring rate and extraction time. The ANN techniques fitted a model for extraction of cadmium with $8,0.9988$ and $6.4 \times 10^{-4}$ neurons, correlation coefficient and mean standard error (MSE), respectively. By using the GA technique, the optimal conditions were achieved at $\mathrm{pH} 7$, extraction volume at $250 \mu \mathrm{L}$, stirring rate of $500 \mathrm{rpm}$ and extraction time of $10 \mathrm{~min}$. Under the optimum conditions, the calibration graph was linear over the range of $0.05-1.00 \mu \mathrm{g} \mathrm{L}{ }^{-1}$ and the limits of detection (LOD) were as small as $0.015 \mu \mathrm{g} \mathrm{mL} \mathrm{m}^{-1}$. The relative standard deviation was $\pm 2.11 \%(\mathrm{n}=7)$ and the enrichment factor was 280 . The developed method was successfully applied to the extraction and determination of cadmium in food samples.
\end{abstract}

Keywords: Artificial Neural Network, Genetic Algorithm, Cadmium, In Syringe Magnet Stirring Assisted Dispersive Liquid-Liquid Microextraction.

\section{INTRODUCTION}

Cadmium $(\mathrm{Cd})$ is a toxic heavy metal that usually entered in the environment due to industrial processes such as alloys, soft solder, photoelectric cells and cadmium-nickel batteries ${ }^{1}$. Cd ions could be influence into the soil, water and agricultural products which is dangerous for human and animals ${ }^{2}$. The Joint FAO/WHO Expert Committee on Food Additives (JECFA) recommended maximum daily consumption of $\mathrm{Cd}$ from various sources (such as food, air and water) should be $3 \mu \mathrm{g} \mathrm{L}^{-1}$. . Many of food products were testing in order to quantification and determination of toxic trace metals to estimate nutritional or toxicological ability of them ${ }^{4}$. Therefore, it is important to detection and quantification of $\mathrm{Cd}$ amount in food sources ${ }^{5}$. The direct determination of $\mathrm{Cd}$ from food samples is difficult due to its low concentration and matrix effects. Sample preparation and preconcentration of analyte from matrix are very necessary to achieve promising researches. Common sample extraction procedures have been applied to various extraction and clean-up techniques including: liquid-liquid extraction (LLE) ${ }^{6}$ and solid phase extraction (SPE) ${ }^{7}$. Although these pretreatment efficiently yield precise results, however, LLE is criticized to be time consuming, labor-intensive, expensive, and hazardous to health due to the large volume of potentially toxic solvents involved. Also, SPE is a simple and rapid technique and has eliminated or decreased most of the disadvantages of LLE, but its operating costs are relatively high. These conventional methods have been significantly replaced in recent decades by solvent miniaturized mircoextraction techniques and solid phase microextraction (SPME), based on the economic and environmental friendly considerations. Dispersive liquid-liquid microextraction (DLLME), as liquid phase microextraction method (LPME), was developed in 2006 by Rezaee and coworkers ${ }^{8}$. In traditional DLLME, a mixture of polar dispersive solvent (water miscible) as a dispersive agent and a high density normally chlorinated organic solvent as extraction solvent is used. After fast injection of this mixture solvent, a cloudy state is formed and hydrophobic species is extracted in a short time in fine droplets. DLLME has been widely used in organic and inorganic species analysis ${ }^{9-11}$. It provides many advantages of high enrichment factor, simplicity, rapidity, easy to operate, low sample volume, low cost and low consumption of organic solvents, but one of the serious drawbacks is its limited choices of extraction solvent. So lately, some researchers make the great effort to use low-density solvents microextraction methods such as: vortexassisted liquid-liquid microextraction, low-density extraction solvent-based solvent terminated dispersive liquid-liquid microextraction ${ }^{12}$, and ultrasound assisted liquid-liquid microextraction ${ }^{13}$. In the mentioned methods, the neck of extraction vessel is relatively wide; therefore it is difficult to collect a thin layer of extractant on the top of the aqueous sample. Recently, in several literatures, different narrow-necked apparatuses are designed which eliminate this difficulty ${ }^{14-16}$. Therefore, developed a simple technique for sample preparations are always considered. In this regard, the use of a syringe or a similar device, as a means of extraction vessel, is useful. In 2013, Horstkotte and coworkers 17 introduced an in-syringe-stirring dispersive liquid-liquid microextraction
(IS-DLLME) method for determination of aluminum in seawater samples. This method has good LOD and RSD, but it is relatively complex. This paper aims to modify IS-DLLME method to simple and a rapid way to collect hydrophobic species from aqueous samples. A glass syringe like apparatus is used to carry out the microextraction, separation and preconcentration of trace amount of the cadmium as ammonium pyrolidine carbamate (APDC) complex (hydrophobic species) from sample solutions only in one step. This device has several advantages: it is simple, economic, without needed centrifuging, and avoids the disperser solvent. The experiment is carried out in a homemade glass syringe with moveable septum. The micro volume of organic solvents is poured on the surface of sample solution and magnetically agitated. After extraction, the extraction solvent is easily separated from the aqueous phase by leaving the extraction system statically for several minutes and lifted it to the narrow section of syringe. In order to obtain the maximum recovery, effective variables of preconcentration process should be optimized. There are many methods to modeling and optimization such as response surface methodology (RSM) ${ }^{18}$, multiple linear regressions (MLR) ${ }^{19}$, artificial neural networks (ANN) ${ }^{20,21}$, fuzzy inference system (FIS) ${ }^{22}$, adaptive neuro-fuzzy inference system (ANFIS) ${ }^{23}$, support vector machine (SVM) ${ }^{24}$, gaussian process (GP) ${ }^{25}$, random forest $(\mathrm{RF})^{26}$ and genetic algorithm $(\mathrm{GA})^{27}$. Artificial neural networks (ANNs) are now used in many areas of science and engineering and considered as promising tool because of their simplicity towards simulation, prediction and modeling. The advantages of ANN are that the mathematical description of the phenomena involved in the process is not required; less time is required for model development than the traditional mathematical models and prediction ability with limited numbers of experiments. Application of ANN to solve environmental engineering problems has been reported in many articles. ANNs were applied in biological wastewater treatment and physicochemical wastewater treatment ${ }^{21}$. In the present work, ANN and GA applied as modeling and optimization techniques, respectively.

\section{EXPERIMENTAL}

\section{Instrumental}

The flame atomic absorption spectrophotometer (Shimadzu AA-680, Japan) equipped with deuterium background correction was used for measurement of cadmium. A hallow cathode lamp (Hamamatsu Photonic Co. Ltd, L233-series) was used as radiation source at maximum absorption (analytical wavelength $228.8 \mathrm{~nm}$ ). Acetylene and air flow rates were 2.2 and $10.0 \mathrm{~L} \mathrm{~min}^{-1}$, respectively. The nebulizer flow rate was $4.0 \mathrm{~mL} \mathrm{~min}{ }^{-1}$. A pH meter (Metrohm Lab-827) was used for solution $\mathrm{pH}$ adjustment.

\section{Reagents}

All solutions were prepared using ultra-pure water $(18.2 \mathrm{M} \Omega)$. The glassware was kept in a $5 \%(\mathrm{v} / \mathrm{v})$ nitric acid solution overnight and subsequently washed with deionized water. All reagents were used in analytical grade. Analytical grade cadmium nitrate and nitrate salts of other cations (Merck, Darmstadt, Germany) were available with high purity and used without further 
purification. Working solutions of $\mathrm{Cd}$ at $\mu \mathrm{g} \mathrm{mL}^{-1}$ level were prepared daily by diluting a $1000 \mu \mathrm{g} \mathrm{mL}^{-1}$ stock solution. The $\mathrm{pH}$ of $\mathrm{Cd}$ solutions was adjusted with the aid of acetate $(\mathrm{pH} 4.0-6.0)$, phosphate $(\mathrm{pH} 2.0-3.0,7.0-9.0)$, and ammonia (pH 10.0-12.0) buffer solutions. Toluene, 1-octanol, 1-decanol, 1-dodecanol, 1-undecanol, hexane and heptane (Merck Darmstadt, Germany) were used in the proposed microextraction method as extraction solvents. Ammonium pyrrolidine dithiocarbamate (APDC) as chelating agent (Merck, Darmstadt, Germany) was prepared by dissolving an appropriate amount of reagent in deionized water.

\section{General procedure}

According to Fig .1a, $50 \mathrm{~mL}$ solution containing cadmium ions in the dynamic range, APDC as complexing agent $\left(1 \times 10^{-5} \mathrm{~mol} \mathrm{~L}^{-1}\right)$ and sodium chloride $(10 \%(\mathrm{w} / \mathrm{v}))$ was adjusted to $\mathrm{pH}=7$ with acetate/acetic acid buffer. Next, the prepared solution was poured in a glass syringe $(8.5 \mathrm{~cm} \times 2.9 \mathrm{~mm}$ i.d. $)$ which end of the syringe was closed with a movable septum (Fig .1a). Then, while the solution is magnetically agitated, $250.0 \mu \mathrm{L}$ of toluene as extraction solvent was injected through the top of the glass syringe into the sample solution by Hamilton gas-tight syringe (Fig .1b). Afterwards, the solution was firmly stirred and a cloudy solution is formed, due to the dispersion of many fine droplets of toluene (Fig .1c). After a few second, the organic phase was collected on the top of the solution (Fig .1d), then it was lifted up in the narrow section of the tube by moving the septum to the top of the syringe (Fig .1e). Finally, $80 \mu \mathrm{L}$ of extraction solvent was manually withdraw by a micro syringe, and was poured into a vial and diluted with $100 \mu \mathrm{L}$ of methanol. Now, the resulting solution introduced to the flame atomic absorption spectrometry for further analysis.
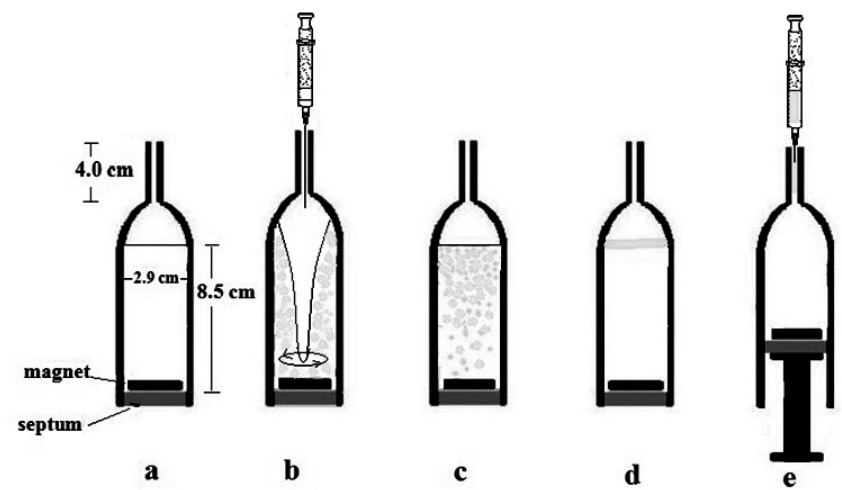

Figure 1. General process: (a) Extraction Vessel b) after adding extraction solvent in the sample solution and stirring it firmly, (c) after extraction of $\mathrm{Cd}$ complex (extraction time, $10 \mathrm{~min}$ ) (d) of extraction solvent being collected on the surface of the sample solution (d) elevating the organic phase by lifting up the septum.

\section{Sample preparation}

The applicability of the IS-MSA-DLLME method was evaluated by analyzing Cd amount in several fruit and vegetable samples. The collected biological samples were washed with double-distilled water for several times, and dried at $100{ }^{\circ} \mathrm{C}$ for $24 \mathrm{~h}$. The grinding process was applied to achieve relatively fine particles and homogeneous sample. For digestion of samples, $1.0 \mathrm{~g}$ of them were weighted in porcelain crucible and placed into the electrical furnace. The temperature was increased gradually to $600{ }^{\circ} \mathrm{C}$ and maintained for $7 \mathrm{~h}$. Afterward, the appropriate amount of $\mathrm{HCl}$ solution $(20 \%)$ was added to digest ash powder. The digested powder was diluted by distilled water to 25 $\mathrm{mL}$ in volumetric flask ${ }^{28}$. The obtained solutions were applied to analyses the cadmium contents of each biological sample by recommended method.

Modeling and optimization by ANN and GA techniques

Based on one-at a time optimization method, four factors including $\mathrm{pH}$ of the solution, extraction volume $(\mu \mathrm{L})$, stirrer rate $(\mathrm{rpm})$ and extraction time $(\mathrm{min})$ were selected as independent variables to modeling and optimization of proposed method. Based out, the range and levels of independent variables are listed in Table 1. Box-Behnken design (BBD) was carried out by Statistica version 10.0 software.

ANN is a modeling tool with non-linear characteristics that is widely using to solve non-linear problems ${ }^{21}$. The ANN is consisting of neurons and connection between them (weights (w) and biases (b)). Typically ANN is included of three layers, which each layer could be containing of several neurons. Usually, a feed forward back propagation network was used in ANN modeling method. in order to ANN modeling, at first a neural network was created and trained to obtain the accurately model with using experimental data (table 1) in MATLAB v. 2012 software toolbox. The correlation coefficient $\left(\mathrm{R}^{2}\right)$ and mean standard error (MSE) were used as evidences of nearness of the suggested model by ANN to actual system. The GA mostly used as a statistic method for solving optimization of multivariate problems in different science such as chemistry and engineering. The GA is able to exploring large amount of input variables due to seeker operators such as crossover and mutation ${ }^{29-31}$.

Table 1. The Box-Behnken design experimental data.

\begin{tabular}{|c|c|c|c|c|}
\hline Factor & Low & $\begin{array}{r}\text { Levels } \\
\text { Central }\end{array}$ & High & \\
\hline$\left(\mathrm{X}_{1}\right) \mathrm{pH}$ & 2 & 5.5 & 9 & \\
\hline$\left(\mathrm{X}_{2}\right)$ Extraction volume $(\mu \mathrm{L})$ & 50 & 150 & 250 & \\
\hline$\left(\mathrm{X}_{3}\right)$ Stirring rate $(\mathrm{rpm})$ & 400 & 800 & 1200 & \\
\hline$\left(\mathrm{X}_{4}\right)$ Extraction time (min) & 2 & 6 & 10 & \\
\hline Runs & $\mathrm{X}_{1}$ & $\mathrm{X}_{2}$ & $\mathrm{X}_{3}$ & $\mathrm{X}_{4}$ \\
\hline 1 & 5.5 & 50 & 1200 & $6^{4}$ \\
\hline 2 & 2.0 & 150 & 1200 & 6 \\
\hline 3 & 2.0 & 150 & 800 & 2 \\
\hline 4 & 2.0 & 150 & 400 & 6 \\
\hline 5 & 9.0 & 50 & 800 & 6 \\
\hline 6 & 5.5 & 150 & 800 & 6 \\
\hline 7 & 9.0 & 150 & 1200 & 6 \\
\hline 8 & 5.5 & 50 & 800 & 10 \\
\hline 9 & 5.5 & 150 & 400 & 2 \\
\hline 10 & 9.0 & 150 & 400 & 6 \\
\hline 11 & 5.5 & 150 & 800 & 6 \\
\hline 12 & 5.5 & 250 & 800 & 10 \\
\hline 13 & 5.5 & 250 & 800 & 2 \\
\hline 14 & 5.5 & 150 & 800 & 6 \\
\hline 15 & 5.5 & 50 & 800 & 2 \\
\hline 16 & 5.5 & 250 & 1200 & 6 \\
\hline 17 & 5.5 & 50 & 400 & 6 \\
\hline 18 & 9.0 & 150 & 800 & 10 \\
\hline 19 & 5.5 & 150 & 1200 & 2 \\
\hline 20 & 5.5 & 150 & 400 & 10 \\
\hline 21 & 2.0 & 150 & 800 & 10 \\
\hline 22 & 5.5 & 250 & 400 & 6 \\
\hline 23 & 2.0 & 50 & 800 & 6 \\
\hline 24 & 2.0 & 250 & 800 & 6 \\
\hline 25 & 9.0 & 250 & 800 & 6 \\
\hline 26 & 9.0 & 150 & 800 & 2 \\
\hline 27 & 5.5 & 150 & 1200 & 10 \\
\hline
\end{tabular}

\section{RESULT AND DISCUSSION}

\section{Selection of extraction solvent}

In order to selection of extraction solvent for proposed microextraction method, the several extraction solvents (low density than water) such as toluene, 1-octanol, 1-decanol, 1-dodecanol, 1-undecanol, hexane and heptane were investigated. According to obtained results (Fig. 2), toluene has the highest extraction efficiency.

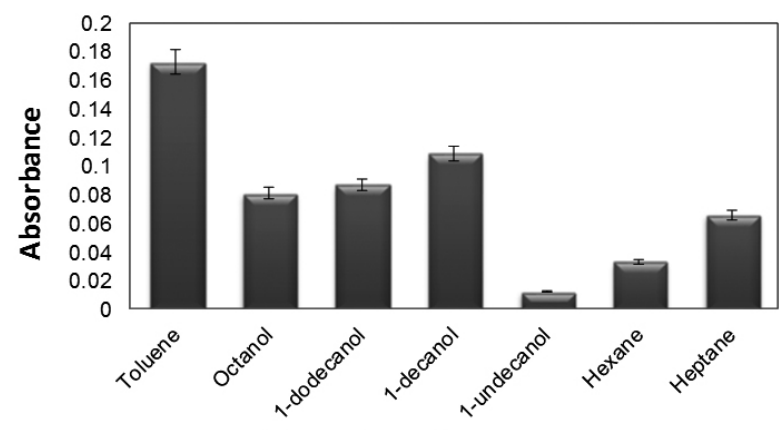

Extraction solvent

Figure 2. Selection of extraction solvent. 


\section{Effect of chelating agent}

In order to studying the effect of APDC concentration on the extraction of Cd by IS-MSA-DLLME method, various concentration of APDC $\left(\mathrm{mol} \mathrm{L}^{-1}\right)$ was investigated. Based on obtained results, the concentration of APDC has no effect on the extraction recovery. Hence, $1 \times 10^{-5} \mathrm{~mol} \mathrm{~L}^{-1}$ of APDC was used for future experiments.

\section{Effect of ionic strength}

Generally, the increase of ionic strength can decrease the solubility of the hydrophobic analyte in sample solutions and can enhance extraction efficiency. To investigate the influence of ionic strength on the extraction efficiency, various experiments were performed by adding varying amounts $(0-4 \mathrm{~mL})$ of $\mathrm{NaCl}(10 \%(\mathrm{w} / \mathrm{v}))$, while the other experimental conditions were kept constant. According to results, salt addition has no significant effect on the extraction recovery. Therefore, salt amount could be constant at $1 \mathrm{~mL}$ of $\mathrm{NaCl}(10 \%$ $(w / v))$ for future experiments.

\section{ANN as modeling technique}

In the present study, experimental data were divided into two set of data included $70 \%$ for training and $30 \%$ for testing by ANN tool (MATLAB v. 2012 software toolbox). ANN must be transforming the input neurons ( $\mathrm{pH}$ of the solution, extraction volume $(\mu \mathrm{L})$, stirring rate $(\mathrm{rpm})$ and extraction time $(\mathrm{min})$ ) into the desired response (extraction efficiency of $\mathrm{Cd}$ ). In order to made the effective ANN, the normalization must be considered for all input and output data ${ }^{32}$. Therefore, the normalization (as a pre-processing step) was carried out for input and output data before training. Normalization was performed between [0.1-0.9] based on follow equation:

$$
X \text { norm }=\frac{(X-X \min )}{(X \max -X \min )}
$$

Where, $\mathrm{X}$ is a variable and $\mathrm{X}_{\min }$ and $\mathrm{X}_{\max }$ are minimum and maximum of variables, respectively.

At first, training of the ANN was carried out for 1000 epochs and correlation coefficient $\left(\mathrm{R}^{2}\right)$ and mean standard error (MSE) were achieved. The $\mathrm{R}^{2}$ is correlation between the actual experimental data values and the ANN predicted values. Also, MSE is the error of this modeling. MSE value must be minimum value for ANN training. The training was completed after 146 epochs and the MSE was found to be $6.4 \times 10^{-4}$. This is indicated very low error in the ANN training model. Moreover, the correlation coefficient $\left(\mathrm{R}^{2}\right)$ was determined to be 0.9988 , which indicated good modeling of ANN with actual experimental data. Based on the minimum MSE and maximum correlation coefficient, the four, eight and one neurons were achieved for the input, hidden and output layer, respectively (Fig. 3).

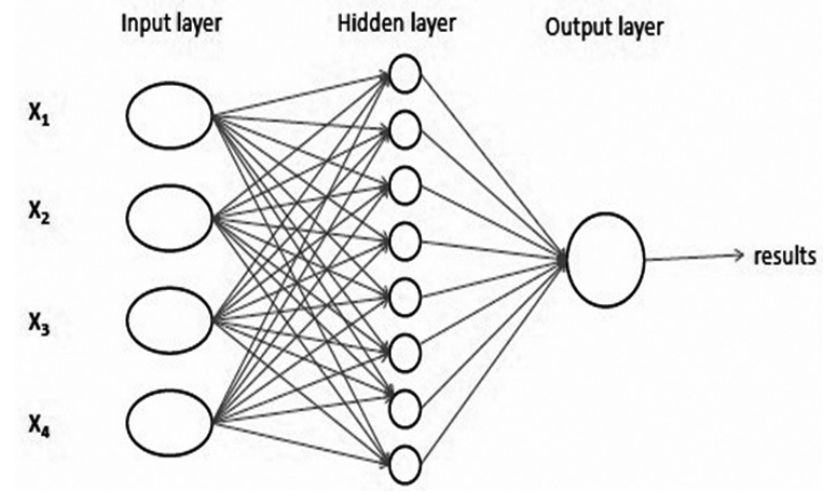

Figure 3. Schematic diagram of the (4-8-1) neural network (four, eight and one neuron in input, hidden and output layer, respectively).

\section{GA as optimization technique}

GA is a powerful optimization technique for linear and non-linear problems. In order to optimization of variables with GA, the 8 neurons resulted from ANN modeling step was set as optimal neuron for GA optimization. The GA was carried out by GA tool (MATLAB version 7.14 software) that different parameters such as population size, crossover probability and mutation probability value were set to $80,0.9$ and 0.01 , respectively. In addition, GA's performance is as follow: the selection, crossover and mutation were chosen as roulette, heuristic and uniform methods, respectively (other parameters chosen as default after several GA studies). After 56 iterations, the optimal conditions were achieved. Fig. 4 shows the maximum and mean fitness function of response. Based on GA, optimal condition were determined as $\mathrm{pH}$ of 7 , extraction solvent volume $(\mu \mathrm{L})$ of 250 , stirrer rate (rpm) equal to 500 and extraction time ( $\mathrm{min})$ of 10 .

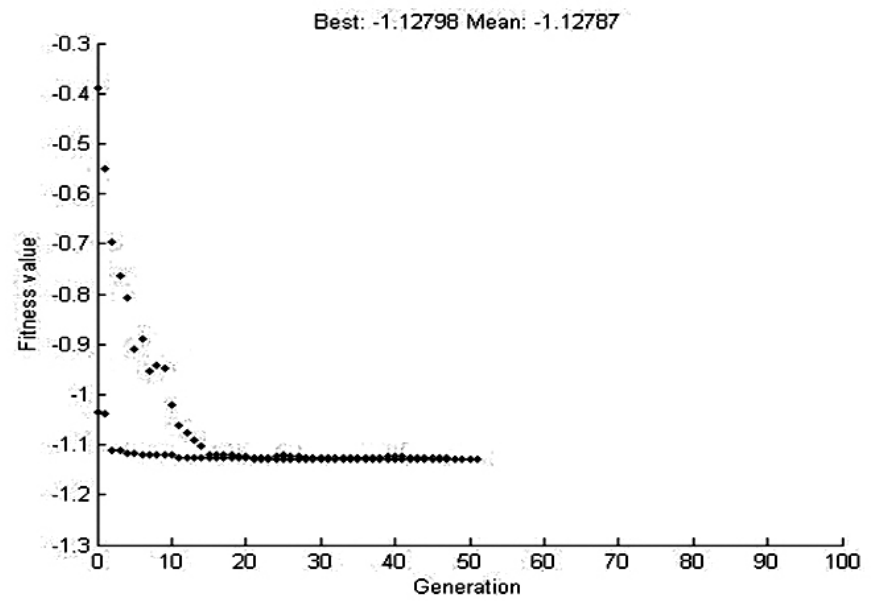

Figure 4. Representative plot for generation for optimization by GA.

\section{Effect of foreign ions}

In optimum conditions which resulted from GA, effect of coexisting ions was carried out in the presence of Cd ions (constant concentration of $0.3 \mu \mathrm{g}$ $\mathrm{L}^{-1}$ ) and different concentration of foreign ions (Table. 2). As can be seen, no interference reveal in determination of Cd by IS-MSA-DLLME method.

Table 2. Effect of coexisting ions on the IS-MSA-DLLME method.

\begin{tabular}{|c|c|c|}
\hline Interfering & Concentration $\left(\mu \mathrm{g} \mathrm{L}^{-1}\right)$ & Recovery $(\%)$ \\
\hline $\mathrm{Co}^{2+}$ & 1000 & 98.3 \\
$\mathrm{Hg}^{2+}$ & 1000 & 99.9 \\
$\mathrm{~Pb}^{2+}$ & 1000 & 98.6 \\
$\mathrm{Pd}^{2+}$ & 1000 & 96.8 \\
$\mathrm{Mn}^{2+}$ & 1000 & 98.4 \\
$\mathrm{Zn}^{2+}$ & 100 & 97.7 \\
$\mathrm{Fe}^{3+}$ & 100 & 96.9 \\
$\mathrm{Ag}^{+}$ & 1000 & 97.3 \\
$\mathrm{Cu}^{2+}$ & 100 & 98.5 \\
$\mathrm{Ni}^{2+}$ & 100 & 98.7 \\
$\mathrm{NO}_{3}^{-}$ & 1000 & 100.6 \\
$\mathrm{Cl}^{-}$ & 1000 & 97.6 \\
\hline
\end{tabular}

\section{Analytical figures of merits}

Based on the acquired results in the optimum variables conditions, the analytical characteristics were obtained. The relative standard deviation (RSD) for 10 replicate measurements of sample solution was $2.11 \%$. The detection limit (LOD), calculated as $3 \mathrm{~S}_{\mathrm{b}} / \mathrm{m}$, where $\mathrm{S}_{\mathrm{b}}$ is the standard deviation of the blank and $\mathrm{m}$ is the slope of the calibration curve, was $0.015 \mu \mathrm{g} \mathrm{L}^{-1}$. The dynamic linear range was from 0.05 to $1.00 \mu \mathrm{g} \mathrm{L}^{-1}$. The enrichment factor (EF) for the proposed method was calculated by the slope ratio of calibration curve after and before the extraction. Analytical characteristics of IS-MSA-DLLME method for cadmium are listed in Table 3 . 
Table 3. Comparison of proposed method with other preconcentration methods for determination of cadmium

\begin{tabular}{|c|c|c|c|c|c|}
\hline Method & $\begin{array}{c}\text { LOD } \\
\left(\mu \mathrm{g} \mathrm{L}^{-1}\right)\end{array}$ & $\mathrm{EF} / \mathrm{PF}$ & $\begin{array}{c}\text { RSD } \\
(\%)\end{array}$ & $\begin{array}{c}\text { Linear range } \\
\left(\mu \mathrm{g} \mathrm{L}^{-1}\right)\end{array}$ & Ref. \\
\hline DLLME & 0.40 & 55.0 & $2.70-1.90$ & $5-100$ & 9 \\
IL-DLLME & 0.40 & 50.0 & 4.30 & $10-200$ & 33 \\
CIAME & 0.12 & 70.0 & 2.40 & $2-200$ & 34 \\
CPE & 0.90 & 13.5 & 4.2 & $3-300$ & 35 \\
CPE & 1.00 & 55.6 & 3.20 & $0.3-100$ & 37 \\
UASEME-SFO & 0.011 & 64.0 & 1.98 & $0.020-0.150$ & 38 \\
IL-USA-DLLME & 0.0074 & 63 & 3.3 & $0.05-1.00$ & This work \\
IS-MSA-DLLME & 0.015 & 280 & 2.11 & & \\
\hline
\end{tabular}

Notes: LOD: Limit Of Detection; RSD: Relative Standard Deviation; EF: Enhancement Factor; PF: Preconcentration Factor; CPE: Cloud Point Extraction; UASEME-SFO: ultrasound-assisted surfactant-enhanced emulsification microextraction solidification floating organic drop; ILUSA-DLLME: Ionic Liquid ultrasonic assisted Dispersive Liquid-Liquid Microextraction; CIAME: Cold Induced Aggregation Microextraction, IL -DLLME: Ionic Liquid Dispersive Liquid-Liquid Microextraction.

\section{Comparison of IS-MSA-DLLME with other methods}

Determination of cadmium in the food samples by the proposed microextration method was compared with the other preconcentration methods used for determination of cadmium by flame atomic absorption spectrometry and the results are shown in Table 3. As can be seen, the proposed method has a low LOD, high enrichment factor, good RSD and linear range. Also, lower density, less toxic and more environmentally friendly organic solvents were used as the extraction solvent in the IS-MSA-DLLME method.

\section{Application of the method}

The proposed method (in optimal conditions of GA) was used for the determination of cadmium in several food samples and the results along with the recovery for the spiked samples were given in Table 4 . The accuracy of the method was verified by the analysis of the samples spiked with the known amount of cadmium.

Table 4. Results of determination of cadmium in food samples with ISMSA-DLLME (in optimal conditions of GA).

\begin{tabular}{|c|c|c|c|}
\hline Sample & $\begin{array}{l}\text { Added } \\
\left(\mu \mathrm{g} \mathrm{L}^{-1}\right)\end{array}$ & $\begin{array}{c}\text { Founded } \\
\left(\mu \mathrm{g} \mathrm{L} \mathrm{L}^{-1}\right)\end{array}$ & $\begin{array}{c}\text { Recovery } \\
(\%)\end{array}$ \\
\hline \multirow[t]{3}{*}{ Cucumber } & - & $143.64 \pm 1.3^{\mathrm{a}}$ & - \\
\hline & 50 & $194.3 \pm 2.3$ & 101.4 \\
\hline & 100 & $244.1 \pm 2.8$ & 100.5 \\
\hline \multirow[t]{3}{*}{ Potato } & - & $197.1 \pm 2.2$ & - \\
\hline & 50 & $247.7 \pm 2.1$ & 101.2 \\
\hline & 100 & $298.7 \pm 2.3$ & 101.6 \\
\hline \multirow[t]{3}{*}{ Tomato } & - & $131.5 \pm 2.5$ & - \\
\hline & 50 & $182.7 \pm 3.1$ & 102.4 \\
\hline & 100 & $232.4 \pm 2.5$ & 100.9 \\
\hline \multirow[t]{3}{*}{ Rice } & - & $112.3 \pm 3.4$ & - \\
\hline & 50 & $163.9 \pm 2.5$ & 103.2 \\
\hline & 100 & $209.5 \pm 2.4$ & 97.2 \\
\hline \multirow[t]{3}{*}{ Spinach } & - & $106.7 \pm 1.7$ & - \\
\hline & 50 & $155.6 \pm 3.3$ & 97.8 \\
\hline & 100 & $205.6 \pm 4.2$ & 98.9 \\
\hline
\end{tabular}

a. Errors correspond to standard deviations of three replicate measurements.

\section{CONCLUSION}

In this proposed method, the magnet stirring was successfully used as a dispersion agent of toluene in aqueous solution for preconcentration of cadmium by APDC. The artificial neural network and genetic algorithm were used to modeling and optimization of the effective parameters in the extraction efficiency of Cd by presented method. This methodologies has several advantages compared to the classical methods in which "one variable at a time" technique is used. It gives a large amount of information from a small number of experiments. Indeed, classical methods are time consuming and a large number of experiments are needed to explain the behavior of a system. This study showed that ANN and GA were suitable techniques to optimization extraction efficiency. This method provides many merits such as: excellent enrichment factors, simplicity, stability, easy to operate, good repeatability and recoveries, low consumption of organic solvents and cost. In this method no dispersive solvent and centrifuging is needed. The above mentioned advantages and good analytical characteristics make this method to be successfully applied to determination of cadmium ions in food samples.

\section{REFERENCES}

1. S. N. Fatemi, S. Tubafard, S. J. Fatemi, B. Nadi, J. Chem. 6, 504 (2009).

2. S.S. Dara., Text book of environmental chemistry and its pollution control, second

ed.S. Chand \& Co. Ltd, New Delhi, 1997.

3. World Health Organization, guidelines for drinking-water quality (3rd ed, vol 1.). Geneve: Recommendations, 2006.

4. A.S. Amin, A.A. Gouda, Food Chem., 132, 518 (2012).

5. A. Mohammadzadeh, M. Ramezani, A. Niazi, Desal. Water Treat, 57, 9745 (2015).

6. S. Nazari, Microchem. J, 90, 107 (2008).

7. R. A. Cherkasov, A. R. Garifzyanov, S.V. Zakharov, A. V. Vinokurov, V. I. Galkin, Russ. J. Gen. Chem., 76, 417 (2006).

8. M. Rezaee, Y. Assadi, M.R.M. Hosseini, E. Aghaee, F. Ahmadi, S. Berijani, J. Chromatogr. A, 1116, 1 (2006).

9. A. Niazi, S. Habibi, M. Ramezani, J. Chil. Chem. Soc., 58, 1899 (2013).

10. R. Heydari, S. Zarabi, Anal. Meth., 6, 8469 (2014).

11. M. Soylak, Y.E. Unsal, Toxicol. Environ. Chem., 94, 1480 (2012).

12. E. Yiantzi, E. Psillakis, K. Tyrovola, N. Kalogerakis, Talanta, 80, 2057 (2010).

13. D. Afzali, B.Bahadori, F. Fathirad, Toxicol. Environ. Chem., 95, 1080 (2013).

14. P. Hashemi, S. Beyranvand, R.S. Mansur, A. R. Ghiasvand, Anal. Chim. Acta, 655, 60 (2009).

15. A. Saleh, Y. Yamini, M. Faraji, M. Rezaee, M. Ghambarian, M, J. Chromatogr. A, 1216, 6673 (2009).

16. P.P. Zhang, Z.G. Shi, Q.W. Yu, Y.Q. Feng, Talanta, 83, 1711 (2011).

17. B. Horstkotte, R. Suárez, P. Solich, V. Cerdà, , Anal. Chim. Acta, 788, 52 (2013).

18. M. Roosta, M. Ghaedi, N. Shokri, A. Daneshfar, R. Sahraei, A. Asghari, Spectrochim. Acta A, 118, 55 (2014).

19. U. Ozdemir, B. Ozbay, S. Veli, S. Zor, Chem Eng J, 178, 183 (2011).

20. S. Elemen, E.P.A. Kumbasar, S. Yapar, Dyes Pigm., 95, 102 (2012).

21. E. S. Elmolla, M. Chaudhuri, M.M. Eltoukhy, J. Hazard. Mater. 179, 127(2010).

22. M. Razani, A. Yazdani-Chamzini, S. H. Yakhchali, Safety Sci., 55, 26 (2013).

23. M. Khalighi, S. Farooq, I.A. Karimi, Chem. Eng. J, 31, 1336 (2012).

24. Y. Liu, F. Sun, Expert Syst. Appl., 40, 4496 (2013).

25. Y. Heo, V.M. Zavala, Energ. Buildings, 53, 7 (2012).

26. A. Hapfelmeier, K. Ulm, Stat. Data Anal, 60, 50 (2013).

27. A. Celekli, H. Bozkurt, F. Geyik, Bioresour. Technol., 129, 396 (2013).

28. A. Mohammadzadeh, A. Samadi-Maybodi, S. Khodadoust, Spectrochim. Acta A, 113, 423 (2013).

29. H. Karimi, F. Yousefi, Fluid Phase Equilib. 336, 374 (2012). 
30. C. Sivapathasekaran, S. Mukherjee, A. Ray, A. Gupta, R. Sen, Bioresour. Technolog, 101, 2884 (2010).

31. R. Soleimani, N.A. Shoushtari, B. Mirza, A. Salahi, Chem. Eng. Res. Des. 91, 883 (2013).

32. D. Bingöl, M. Hercan, S. Elevli, E. Kılı̨̧, Bioresour. Technol., 112, 111 (2012).

33. S. Khan, M. Soylak, T.G. Kazi, Toxicol. Environ. Chem., 95, 1069 (2013).
34. M. Shamsipur, M. Ramezani, A.A. Miran Beigi, T. Poursaberi, Indian J. Chem., Sect. A, 51, 825 (2012).

35. G. Xiang, S. Wen, X. Wu, X. Jiang, L. He, Y. Liu, Food Chem., 132, 532 (2012).

36. A. Afkhami, T. Madrakian, H. Siampour, J. Hazard..Mater., 138, 269 (2006).

37. M. Ezoddin, T. Taghizadeh, B. Majidi, Environ. Technol., 35, 2401 (2014).

38. S. Li, S. Cai, W. Hu, H. Chen, H. Liu, Spectrochim. Acta B, 64, 666 (2009). 